\title{
The Epidemiology of Hemolytic Uremic Syndrome: Clinical Presentation, Laboratory Findings, Management and Outcomes
}

\author{
Khalfan Alshaailii ${ }^{1}$, Issa Al Salmi ${ }^{1}{ }^{*}$, AbdelMasiah Metry ${ }^{1}$, Faisal Al Ismaili ${ }^{1}$, Alan Hola ${ }^{1}$ and Suad Hannawi ${ }^{1}$
}

${ }^{1}$ Department of Renal Medicine, Royal Hospital, Muscat, Oman

Received: July 3, 2018; Accepted: July 12, 2018; Published: July 18, 2018

*Corresponding author: Issa Al Salmi, Department of Renal Medicine, Royal Hospital, Muscat, Oman, E-mail: isa@ausdoctors.net

\begin{abstract}
Introduction: Hemolytic-uremic syndrome (HUS) is a disease that has been described as a triad of hemolytic anemia, thrombocytopenia and renal impairment. There are two types of HUS, typical and atypical. HUS remains a leading cause of acute renal injury in children and is increasingly recognized as a cause of renal failure in adults. In our study we evaluated the demographic features, clinical characteristics, management and outcome of HUS in Omani population presented in the main tertiary hospital.
\end{abstract}

Methodology: This is a retrospective descriptive study evaluating all cases of Hemolytic Uremic Syndrome (HUS) that have been admitted at Royal Hospital (RH) Oman in the period between 2006 and 2015.

Results: Thirty six patients identified. The mean age (SD) of 10.68 (14.07) years. Eighteen (50\%) presented with abdominal pain, nausea, vomiting and diarrhea, $9(25 \%)$ with hypertension, $23(64 \%)$ with acute kidney injury (AKI), $6(16.67 \%)$ with seizure, $2(5.56 \%)$ with confusion and $1(2.78 \%)$ with cerebrovascular accident (CVA). Twenty-one (58.33\%) diagnosed as typical HUS of which 19 with Shiga toxin producing Escherichia Coli (STEC) HUS and 2 had post Streptococal HUS. Six (16.67\%) diagnosed with aHUS, 2 (5.56\%) with HELLP , 2 (5.56\%) with G6PD, 3 (8.33\%) with Autoimmune hemolytic anemia (AIHA ), one (2.78\%) with congenital TTP and 1 (2.78\%) with post partum HUS.Twenty three (63.89\%) needed renal replacement therapy (RRT), while remaining $13(36.11 \%)$ did not require RRT. Eleven $(30.56 \%)$ received plasma exchange, $5(13.89 \%)$ received Eculizumab while $2(5.56 \%)$ received plasma infusion and $1(2.78 \%)$ patient received Rituximab. The majority $22(61.11 \%)$ had partial recovery after treatment, 5 (13.89\%) had compelte recovery and 3 $(8.33 \%)$ ended with end stage kidney disease (ESKD) and $1(2.78 \%)$ died from hypertensive crises.

Conclusion: The study results showed that HUS populations were mostly due to Shiga toxin producing Escherichia Coli (STEC). It showed that HUS population were young, mostly male and only $25 \%$ have known medical comorbidities at time of presentation. Also, the majority presented with AKI requiring dialysis, of which PD was main stay of therapy. The duration of RRT and recovery time was almost a month period.

\section{Introduction}

Hemolytic-uremic syndrome (HUS) is a disease that has been initially identified in 1955 and described as a triad of sudden drop of hemoglobulin (hemolytic anemia), thrombocytopenia and kidney dysfunction $[1,2]$. It affects predominantly, but not exclusively, children [3-6]. There are two types of HUS. Typical HUS that follows infection like E. coli OH157:H7, Shiga toxin and others $[3,4,6,7]$. Atypical HUS (aHUS) defined as non-Shigatoxin-HUS that results from dysregulation of the complement alternative pathway and has a less favorable outcome $[8,9]$.

HUS and thrombotic thrombocytopenic purpura (TTP) are the two main variants of thrombotic microangiopathies (TMA) and related disorders [10]. HUS remains a leading cause of acute kidney injury in North American children and is increasingly recognized as a cause of kidney dysfunction in adults. The annual incidence of HUS in the United States is approximately 2.2 cases per 100,000 population, as well as in Europe [11].

There was no study done in Oman and very limited from the whole region about HUS. Hence, the objective of our study is to evaluate the demographic features, clinical characteristics, management and outcome of HUS in Omani population presented in the main tertiary hospital.

\section{Methodology}

This is a retrospective descriptive study evaluating all cases of HUS that have been admitted at Royal Hospital (RH) Oman in the period between 2006 and 2015 .

A list of all patients with provisional International statistical classification of disease and related health problems (ICD-10) diagnosis of HUS during that period was retrieved from the $\mathrm{RH}$ electronic medical record system, 36 patients found and those were studied in details. Subsequently they were divided into three main categories according to the final ICD-10, typical HUS, aHUS and hemolysis with deranged renal function due to other causes.

In these patients the variables including demographics, comorbidities at the time of presentation including Hypertension (HTN), Diabetes Mellitus (DM), chronic kidney disease (CKD), Obesity and Dyslipidemia. Also, clinical presentation that include nausea \& vomiting, diarrhea, abdominal pain, gastroenteritis, colitis, confusion, encephalopathy, seizure, stroke, hypertension and acute kidney injury were recorded. In addition, laboratorial investigation like (complete blood count, blood film, C- reactive 
protein (CRP), Erythrocytic Sedimentation Rate (ESR) Bone \& liver \& coagulation profile, renal functions, complements profile, complements function, genetic study, radiological assessment including abdominal Ultrasound were retrieved. Also, various management and outcomes were recorded.

The process of data entry and analysis were always rechecked by two researchers. An epidemiologist was involved throughout the study. This started from the first meeting and conception of the research idea till the end of the study. Quality control data was done as per our institute research guidelines. Statistical analysis was completed using Stata software, Chicago, Ill. USA.

\section{Results}

The majority of patients were young with a mean age (SD) of 10.68 (14.07) years. Youngest was 6 months old while the oldest was 46 years old, and 21 (58.33\%) patients were males. Majority were from outside the capital $28(77.78 \%)$ and the rest from Muscat region 8 (22.22\%).
Most of the patients had no medical co-morbidities but 8 (25\%) had the following: 3 (8.33\%) were hypertensive (HTN), 2 (5.56\%) were known to have chronic kidney disease (CKD), $2(5.56 \%)$ were obese and only $1(2.78 \%)$ was a known dyslipidemic.

Eighteen (50\%) of the patients presented with abdominal pain, nausea, vomiting and diarrhea, 9 (25\%) patients presented with HTN, 23 (64 \%) patients presented with acute kidney injury (AKI). Six patients $(16.67 \%)$ presented with seizure while 2 $(5.56 \%)$ had confusion and only $1(2.78 \%)$ had cerebrovascular accident (CVA).

Various laboratory parameters were done at the time of initial presentation and diagnosis and after receiving the various management therapies, as shown in tables 1 and 2 . The tables illustrates the improvement of these laboratory measurement with time.

Table 1: Comparison in blood tests variables before (mean 1) and after treatment (mean2) Hb (Hemoglobin) TLC ( Total leucocytic count)) ANC (Absolute Neutrophilic count ) LC (Lymphocytic count) MC(Monocytic count) Plt (Platelets count)RC (Reticulocytic count) ESR (Erythrocytic sedimentation rate) PT (Prothrombin time) APTT (Activate partial thromboplastin time), TT (Thrombin time)

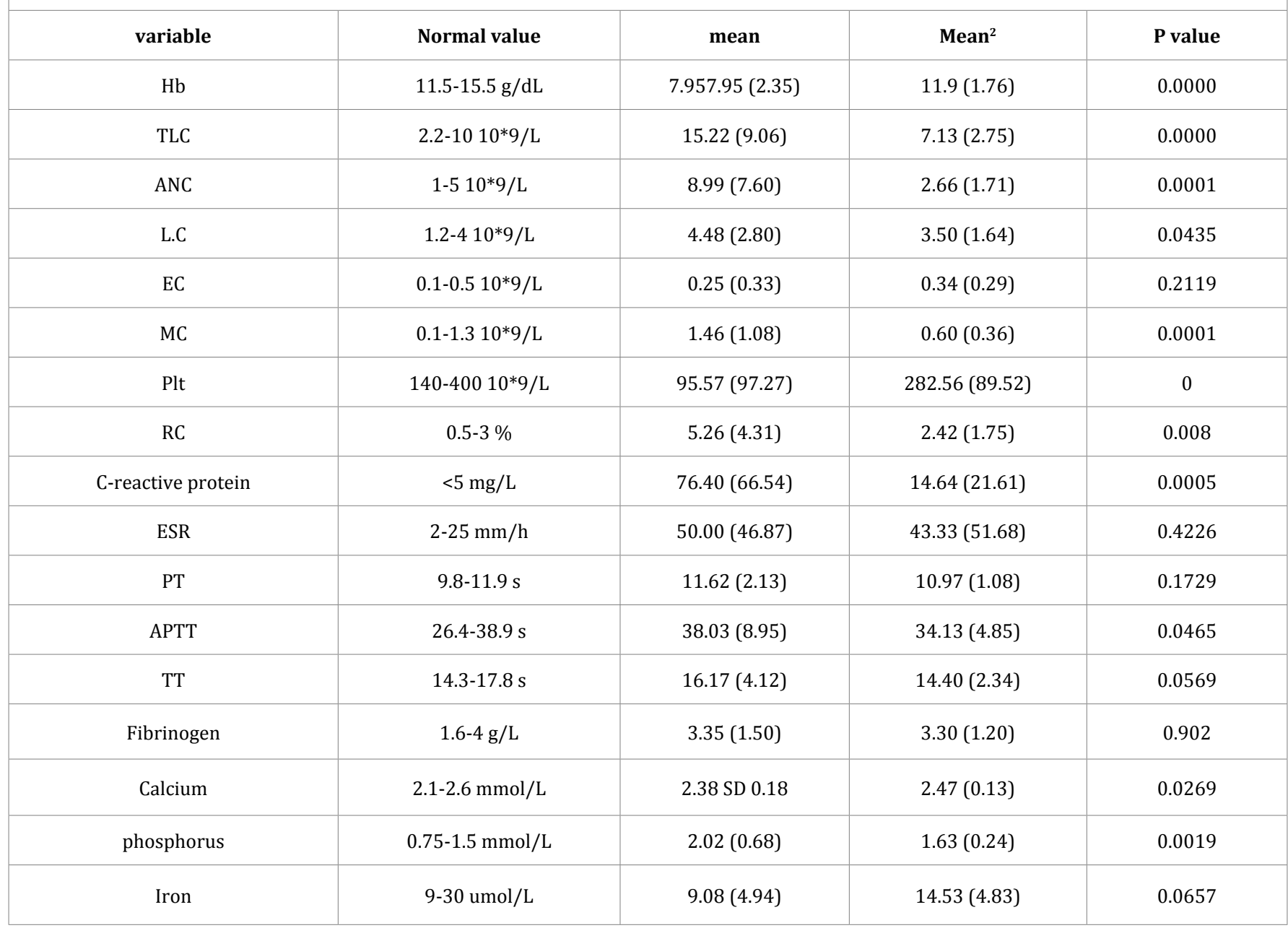


The Epidemiology of Hemolytic Uremic Syndrome: Clinical Presentation,

\begin{tabular}{|c|c|c|c|c|}
\hline Transferrin saturation $\%$ & $20-50 \%$ & $19.22(8.41)$ & $28.78(13.60)$ & 0.1755 \\
\hline Bilirubin & $0-20 \mathrm{umol} / \mathrm{L}$ & $33.68(81.43)$ & $8.65(5.19)$ & 0.0884 \\
\hline Alanine transferase & $0-40(\mathrm{iU}) / \mathrm{L}$ & $100.59(123.85)$ & $28.78(38.20)$ & 0.0038 \\
\hline Alkaline phosphatase & $40-150(\mathrm{iU}) / \mathrm{L}$ & $187.84(243.75)$ & $196.16(83.85)$ & 0.8583 \\
\hline Albumin & $35-50 \mathrm{~g} / \mathrm{L}$ & $27.47(7.13)$ & $36.47(4.21)$ & 0 \\
\hline Parathyroid hormone & $1.6-6.9 \mathrm{pmol} / \mathrm{L}$ & $19.56(15.59)$ & $9.6(10.29)$ & 0.2480 \\
\hline Urine protein creatinine ratio & $<20 \mathrm{mg} / \mathrm{mmol}$ & 2088.86(3700.59) & $75.46(133.91)$ & 0.0224 \\
\hline Urea & $2.5-6.7 \mathrm{mmol} / \mathrm{L}$ & $23.73(13.33)$ & $7.14(5.49)$ & 0.0000 \\
\hline Creatinine & $45-100 \mathrm{umol} / \mathrm{L}$ & $304.88(205.48)$ & $96.33(129.23)$ & 0.0000 \\
\hline Estimated glomerular filtration rate & $\mathrm{ml} / \mathrm{min} / 1.73 \mathrm{~m} 2$ & $22.73(24.72)$ & $63.33(25.16)$ & 0.0000 \\
\hline Bicarbonate & $22-29 \mathrm{mmol} / \mathrm{L}$ & $16.12(5.78)$ & $23.36(3.34)$ & 0.0000 \\
\hline Uric acid & $200-400 \mathrm{umol} / \mathrm{L}$ & $619.75(248.73)$ & $348.38(142.21)$ & 0.0420 \\
\hline Compliment 3 & $820-1850 \mathrm{mg} / \mathrm{L}$ & $862.54(282.55)$ & $1058.45(418.99)$ & 0.1530 \\
\hline Compliment 4 & $150-530 \mathrm{mg} / \mathrm{L}$ & 253.17 (212.69) & 269.5 (128.28) & 0.7918 \\
\hline Haptoglobin & $140-2580 \mathrm{mg} / \mathrm{L}$ & $294.6(579.551)$ & $968.25(761.12)$ & 0.0003 \\
\hline Lactate dehydrogenase & $125-240(\mathrm{iU}) / \mathrm{L}$ & $1859.03(1038.86)$ & $244.17(55.54)$ & 0.0000 \\
\hline
\end{tabular}

Table 2: Blood film variables changes (\%) before and after treatment.

\begin{tabular}{|c|c|c|}
\hline Item & Before treatment & After treatment \\
\hline Anemia & $94.29 \%$ & $40.63 \%$ \\
\hline Leukocytosis & $47.06 \%$ & $9.68 \%$ \\
\hline Toxic granulation & $57.14 \%$ & $38.46 \%$ \\
\hline Thrombocytopenia & $83.33 \%$ & $19.23 \%$ \\
\hline Fragmented red blood cells & $64.71 \%$ & $19.05 \%$ \\
\hline
\end{tabular}

The blood film showed significant improvement of anemia, thrombocytopenia and reduction of percentage of schistocytes between the time at presentation and after treatment, as shown in table 2 .

Twenty-one (58.33\%) patients were diagnosed as typical HUS of which 19 were diagnosed as Shiga toxin producing Escherichia Coli (STEC) HUS, while the remaining 2 had post Streptococal HUS.

Six (16.67 \%) patientes were diagnosed as aHUS, 2 (5.56\%) patients with HELLP , 2 (5.56 \%) with G6PD, 3 (8.33 \%) with Autoimmune hemolytic anemia (AIHA), one (2.78\%) with congenital TTP and one (2.78\%) was diagnosed as post partum HUS.
Twenty three (63.89\%) patients needed renal replacement therapy (RRT), while remaining 13 (36.11\%) did not require RRT. In the typical HUS, 18 from 21 (86\%) patients , aHUS 4 from 6( $67 \%)$ and one patient from 2 (50\%) with HELLP.

Sixteen of 23 patients (69.5\%) received peritoneal dialysis (PD) (all of them with typical HUS ), while the remaining 7 (30.5 $\%$ ) received HD (3 patient with typical HUS, 3 patients with aHUS and one patient with HELLP).

Eleven patients $(30.56 \%)$ received plasma exchange, 5 (13.89\%) patients received Eculizumab while two patients received plasma infusion $(5.56 \%)$ and one $(2.78 \%)$ patient received Rituximab. 
The mean (SD) of the RRT duration was 33.2 (31.8) days, while the recovery time was 36 (33.7) days.

Five (16.67 \%) patients had normal renal function on presentation and remain same through the treatment course, while the majority of the patients, $22(61.11 \%)$ had partial recovery after treatment, 5 (13.89\%) had compelte recovery and $3(8.33 \%)$ ended with end stage kidney disease (ESKD) and 1 $(2.78 \%)$ died from hypertensive crises.

\section{Discussion}

This is the first study reporting HUS from Oman. HUS triad, of hemolytic anemia, thrombocytopenia and kidney dysfunction was established, from sudden drop in $\mathrm{Hb}$, decreased platelets and abnormal kidney function as shown in table 1-3. The study results showed that HUS populations were mostly due to Shiga toxin producing Escherichia Coli (STEC). It showed that HUS population were young, mostly male and only $25 \%$ have known medical comorbidities at time of presentation. Also, the majority presented with AKI requiring dialysis, of which PD was main stay of therapy. The duration of RRT and recovery time was almost a month period.

Previous studies showed that the average annual incidence for HUS of 0.71 per 100,000 children in Germany while it was 0.7 cases $/ 100,000$ and 0.6 cases $/ 100,000$ in France and Australia, respectively [3, 12]. The highest HUS incidence worldwide occurs in Argentina, although exact incidence rates are unclear $[6,13,14]$. A relatively lower incidence was reported in Italy $[0.2$ cases/100,000 children) [5, 15].

Our study results were in concordance with the world-wide pattern of the disease's young age incidence [1, 3, 7, 16-19], with mean age (SD) 10.68 (14.07) years. We also found that there was relatively higher incidence of the disease in males (58.33\%) which is similar to what was found by other researchers in our region, Saudi Arabia and Kuwait [16] whereas other researchers reported relative predominance of females $[18,20]$.

In the present study, the total white cell count was very high with a mean (SD) 15.2 (9.1) and neutrophilic leukocytosis of 8.99 (7.7) at time of presentation. Researchers noted that the presence of high polymorphonuclear neutrophil counts in patients with HUS indicates a poor prognosis [13, 21-25]. The important role of leukocytes in the pathogenesis of HUS and its endothelial dysfunction leading to HUS was also noted to be of vital role [24-26]. In vitro experiments, STEC binds to leukocytes and is transferred by them to endothelial cells [20,24, 25]. Accordingly, STEC also has been detected on the surface of circulating leukocytes of patients with HUS [21, 22, 27], and in a murine HUS model, STEC 2 induced neutrophilia and neutrophil activation $[28,29]$. Also, in clinical studies, initial leukocytosis has been described as a predictor for development of HUS [13, $23,26,30,31]$.

AKI is a common manifestation of TMAs, although rarely a severe feature of TTP [2]. Extra renal manifestations are reported in TMAs, with the published data referring primarily to those observed in complement-mediated aHUS and STEC-HUS, although it is not known whether they are a consequence of the TMA, a direct effect of complement activation or shiga toxin, or complications of AKI, such as severe hypertension and uremia [32].

Though majority of our studied patients had no co-morbid conditions, however it is possible that those who had preexisting other medical conditions like HTN, CKD, dyslipidemia and obesity might have contributed to poor outcomes. Gerber et al found that diarrhea was present in $91 \%$ of patients [20]. Neurologic symptoms, mainly seizures and stupor were found in $25 \%$ of patients. Hypertension during the acute course occurred in $15 \%$ of case subjects [20]. In our study we found that $64 \%$ of patients had AKI, $50 \%$ with gastrointestinal symptoms, $25 \%$ with HTN, $16.67 \%$ with seizure, $5.56 \%$ with confusion and $2.78 \%$ with cerebrovascular accident (CVA).

Studies have shown that the indication for initiating dialysis is variable. In the present study, two third (63.9\%) of patients needed RRT, of which the majority were on PD (69.5\%). Most centers in Germany and Austria start dialysis on the day of admission if oliguria or anuria is present. Data from France (53\%) [4] and the United States (55\%) [18, 33] showed a lower portion of dialyzed patients than in Germany, Austria, and Australia $(63 \%)[2,8,15,20]$

Several reports indicate that the duration of dialysis is a predictor for long-term outcome [2, 8, 15, 34, 35]. This study found that the mean duration of RRT was 33.2 SD (31.8) days while the mean time to recovery was 36 SD (33.7) days. These findings are similar to those reported from neighboring countries $[16,19]$. However, another study reported a lower mean duration of dialysis of 18 days (range three to 56 days) [36].

While we had a low mortality of $2.78 \%$, which is similar to a Saudi report of $3 \%$ mortality rate [36]. Other studies reported rates as high as $(6 \%)$ in the United Stated $[2,35]$, followed by Australia (4\%) [8, 12], Germany (2\%), and France (1.4\%) [3].

Our study has few limitations including that is it retrospective, small sample size and possibly not including all cases due to lack of a database registry in Oman. Another problem is poor documentation and lack of continuity within a fragmented network of both public and private providers that also may underestimate the incidence and prevalence of this health problems. However complicated cases usually referred to our center.

\section{Conclusion}

It is the first report of HUS from Oman. Our results were in a concordance with the world-wide pattern of the disease's young age incidence and disease presentation and complications with lower mortality rates. It would be prudent to establish a national Oman TMA registry for better capturing of cases and to provide more extensive and accurate data to the health authority for future health care planning. 


\section{Acknowledgement}

The authors would like to acknowledge the help and support of the Oman Medical Specialty Board, particularly the Research Department.

\section{References}

1. Boyer $\mathrm{O}$, Niaudet P. Hemolytic uremic syndrome: new developments in pathogenesis and treatment. Int J Nephrol. 2011:908407. doi: $10.4061 / 2011 / 908407$

2. Spinale JM, Ruebner RL, Copelovitch L, Kaplan BS. Long-term outcomes of Shiga toxin hemolytic uremic syndrome. Pediatr Nephrol. 2013;28(11):2097-2105. doi: 10.1007/s00467-012-2383-6

3. Decludt B, Bouvet P, Mariani-Kurkdjian P, Grimont F, Grimont PA, Hubert B, et al. Haemolytic uraemic syndrome and Shiga toxin-producing Escherichia coli infection in children in France. The Societe de Nephrologie Pediatrique. Epidemiol Infect. 2000;124(2):215-220.

4. Espie E, Grimont F, Mariani-Kurkdjian P, Bouvet P, Haeghebaert S, Filliol I, et al. Surveillance of hemolytic uremic syndrome in children less than 15 years of age, a system to monitor 0157 and non-0157 Shiga toxin-producing Escherichia coli infections in France, 19962006. Pediatr Infect Dis J. 2008;27(7):595-601. doi: 10.1097/ INF.0b013e31816a062f

5. Gianviti A, Rosmini F, Caprioli A, Corona R, Matteucci MC, Principato $\mathrm{F}$, et al. Haemolytic-uraemic syndrome in childhood: surveillance and case-control studies in Italy. Italian HUS Study Group. Pediatr Nephrol. 1994;8(6):705-709.

6. Lopez EL, Diaz M, Grinstein S, Devoto S, Mendilaharzu F, Murray $\mathrm{BE}$, et al. Hemolytic uremic syndrome and diarrhea in Argentine children: the role of Shiga-like toxins. J Infect Dis. 1989;160(3):469475.

7. Brandal LT, Wester AL, Lange H, Lobersli I, Lindstedt BA, Vold L, et al. Shiga toxin-producing escherichia coli infections in Norway, 19922012: characterization of isolates and identification of risk factors for haemolytic uremic syndrome. BMC Infect Dis. 2015;15:324. doi: 10.1186/s12879-015-1017-6

8. Durkan AM, Kim S, Craig J, Elliott E. The long-term outcomes of atypical haemolytic uraemic syndrome: a national surveillance study. Arch Dis Child. 2016;101(4):387-391. doi: 10.1136/ archdischild-2015-309471

9. Grumach AS, Kirschfink M. Are complement deficiencies really rare? Overview on prevalence, clinical importance and modern diagnostic approach. Mol Immunol. 2014;61(2):110-117. doi: 10.1016/j.molimm.2014.06.030

10. Clark WF. Thrombotic microangiopathy: current knowledge and outcomes with plasma exchange. Semin Dial. 2012;25(2):214-219. doi: 10.1111/j.1525-139X.2011.01035.x

11. Noris M, Remuzzi G. Hemolytic uremic syndrome. J Am Soc Nephrol. 2005;16(4):1035-1050. doi: 10.1681/ASN.2004100861

12.Elliott EJ, Robins-Browne RM, O'Loughlin EV, Bennett-Wood V, Bourke J, Henning P, et al. Nationwide study of haemolytic uraemic syndrome: clinical, microbiological, and epidemiological features. Arch Dis Child. 2001;85(2):125-131
13.Lopez EL, Contrini MM, Glatstein E, Ayala SG, Santoro R, Ezcurra $\mathrm{G}$, et al. An epidemiologic surveillance of Shiga-like toxin-producing Escherichia coli infection in Argentinean children: risk factors and serum Shiga-like toxin 2 values. Pediatr Infect Dis J. 2012;31(1):2024. doi: 10.1097/INF.0b013e31822ea6cf

14.Lopez EL, Prado-Jimenez V, O’Ryan-Gallardo M, Contrini MM. Shigella and Shiga toxin-producing Escherichia coli causing bloody diarrhea in Latin America. Infect Dis Clin North Am. 2000;14(1):4165.

15.Gianviti A, Tozzi AE, De Petris L, Caprioli A, Rava L, Edefonti A, et al. Risk factors for poor renal prognosis in children with hemolytic uremic syndrome. Pediatr Nephrol. 2003;18(12):1229-1235.

16.Al Harbi NN, Elawad ME, Al Homrany MA. Hemolytic-uremic syndrome in asir region. J Family Community Med. 1996;3(1):53-57.

17. Chemli J, Hassayoun S, Krid S, Ghali N, Abroug S, Zakhama A, et al. [Uremic and haemolytic syndrome in children: study of 17 cases]. Tunis Med. 2008;86(5):479-85.

18.Gould LH, Demma L, Jones TF, Hurd S, Vugia DJ, Smith K, et al. Hemolytic uremic syndrome and death in persons with Escherichia coli 0157:H7 infection, foodborne diseases active surveillance network sites, 2000-2006. Clin Infect Dis. 2009;49(10):1480-1485. doi: 10.1086/644621

19. Al-Eisa A, Al-Hajeri M. Hemolytic uremic syndrome in Kuwaiti Arab children. Pediatr Nephrol. 2001;16(12):1093-1098.

20.Gerber A, Karch H, Allerberger F, Verweyen HM, Zimmerhackl LB. Clinical course and the role of shiga toxin-producing Escherichia coli infection in the hemolytic-uremic syndrome in pediatric patients, 1997-2000, in Germany and Austria: a prospective study. J Infect Dis. 2002;186(4):493-500.

21. Brigotti M, Caprioli A, Tozzi AE, Tazzari PL, Ricci F, Conte R, et al. Shiga toxins present in the gut and in the polymorphonuclear leukocytes circulating in the blood of children with hemolyticuremic syndrome. J Clin Microbiol. 2006;44(2):313-317. doi: 10.1128/JCM.44.2.313-317

22. Brigotti M, Carnicelli D, Ravanelli E, Barbieri S, Ricci F, Bontadini A, et al. Interactions between Shiga toxins and human polymorphonuclear leukocytes. J Leukoc Biol. 2008;84(4):10191027. doi: 10.1189/jlb.0308157

23. Brigotti M, Tazzari PL, Ravanelli E, Carnicelli D, Rocchi L, Arfilli V, et al. Clinical relevance of shiga toxin concentrations in the blood of patients with hemolytic uremic syndrome. Pediatr Infect Dis J. 2011;30(6):486-490. doi: 10.1097/INF.0b013e3182074d22

24.Petruzziello-Pellegrini TN, Marsden PA. Shiga toxin-associated hemolytic uremic syndrome: advances in pathogenesis and therapeutics. Curr Opin Nephrol Hypertens. 2012;21(4):433-440. doi: 10.1097/MNH.0b013e328354a62e

25.Petruzziello-Pellegrini TN, Moslemi-Naeini M, Marsden PA. New insights into Shiga toxin-mediated endothelial dysfunction in hemolytic uremic syndrome. Virulence. 2013;4(6):556-563. doi: 10.4161/viru.26143

26. Fernandez GC, Gomez SA, Rubel CJ, Bentancor LV, Barrionuevo $\mathrm{P}$, Alduncin $\mathrm{M}$, et al. Impaired neutrophils in children with the typical form of hemolytic uremic syndrome. Pediatr Nephrol. 2005;20(9):1306-1314 
27. Brigotti M, Tazzari PL, Ravanelli E, Carnicelli D, Barbieri S, Rocchi L, et al. Endothelial damage induced by Shiga toxins delivered by neutrophils during transmigration. J Leukoc Biol. 2010;88(1):201210. doi: 10.1189/jlb.0709475

28. Fernandez GC, Lopez MF, Gomez SA, Ramos MV, Bentancor LV, Fernandez-Brando RJ, et al. Relevance of neutrophils in the murine model of haemolytic uraemic syndrome: mechanisms involved in Shiga toxin type 2-induced neutrophilia. Clin Exp Immunol 2006;146(1):76-84.

29. Fernandez GC, Rubel C, Dran G, Gomez S, Isturiz MA, Palermo MS Shiga toxin-2 induces neutrophilia and neutrophil activation in a murine model of hemolytic uremic syndrome. Clin Immunol. 2000;95(3):227-234.

30.Fernandez GC, Gomez SA, Ramos MV, Bentancor LV, FernandezBrando RJ, Landoni VI, et al. The functional state of neutrophils correlates with the severity of renal dysfunction in children with hemolytic uremic syndrome. Pediatr Res. 2007;61(1):123-128.
31. Anjay MA, Anoop P, Britland A. Leukocytosis as a predictor for progression to haemolytic uraemic syndrome in Escherichia coli 0157:H7 infection. Arch Dis Child. 2007;92(9):820-823.

32. BrocklebankV, Wood KM, Kavanagh D. Thrombotic Microangiopathy and the Kidney. Clin J Am Soc Nephrol. 2018;13(2):300-317. doi: 10.2215/CJN.00620117

33. Kaplan BS. An update on the hemolytic uremic syndrome. Saudi J Kidney Dis Transpl. 2000;11(4):537-42.

34.Brunelli SM, Claxton A, Mehta S, Anum EA. Consequences of hemolytic uremic syndrome among hemodialysis patients. J Nephrol. 2015;28(3):361-367. doi: 10.1007/s40620-014-0149-x

35.Siegler R, Oakes R. Hemolytic uremic syndrome; pathogenesis, treatment, and outcome. Curr Opin Pediatr. 2005;17(2):200-204.

36.Elzouki AY, Mirza K, Mahmood A, Al-Sowailem AM. Hemolytic uremic syndrome - clinical aspects and outcome of an outbreak: Report of 28 cases. Ann Saudi Med. 1995;15(2):113-116. 